\title{
Article \\ Effects of Grain Refinement on the Low-Cycle Fatigue Behavior of IN792 Superalloys
}

\author{
Beining Du ${ }^{1,2}$, Liyuan Sheng ${ }^{1,2, * \mathbb{D}}$, Chuanyong Cui ${ }^{3, *}$, Ziyang $\mathrm{Hu}^{4}$ and Xiaofeng Sun ${ }^{3}$ \\ 1 Shenzhen Institute, Peking University, Shenzhen 518057, China; bndu10s@alum.imr.ac.cn \\ 2 PKU-HKUST Shenzhen-HonKong Institute, Shenzhen 518057, China \\ 3 Institute of Metal Research, Chinese Academy of Sciences, Shenyang 110016, China; xfsun@imr.ac.cn \\ 4 Shenzhen Yezhan Electronics Co., Ltd., Shenzhen 518110, China; zyhu10s@alum.imr.ac.cn \\ * Correspondence: lysheng@yeah.net (L.S.); chycui@imr.ac.cn (C.C.)
}

Citation: Du, B.; Sheng, L.; Cui, C.; $\mathrm{Hu}, \mathrm{Z}$.; Sun, X. Effects of Grain

Refinement on the Low-Cycle Fatigue Behavior of IN792 Superalloys.

Crystals 2021, 11, 892.

https://doi.org/10.3390/

cryst11080892

Academic Editors: Adam Zieliński, Grzegorz Golański and Marek Sroka

Received: 9 July 2021

Accepted: 28 July 2021

Published: 30 July 2021

Publisher's Note: MDPI stays neutral with regard to jurisdictional claims in published maps and institutional affiliations.

Copyright: (c) 2021 by the authors. Licensee MDPI, Basel, Switzerland. This article is an open access article distributed under the terms and conditions of the Creative Commons Attribution (CC BY) license (https:/ / creativecommons.org/licenses/by/ $4.0 /)$.
Abstract: The Ni-based IN792 superalloy is widely applied as a component in industrial turbines and aircraft engines due to its good high-temperature properties and excellent corrosion resistance. Since these components have to suffer from cyclic thermal and mechanical stresses during service, the high-temperature fatigue failure becomes one of the major factors affecting their service lives. Grain refinement has been considered as an effective way to improve the mechanical performance of superalloys. However, due to the complexity of alloy composition, microstructure and service condition, there is no unified theory about the influence of grain refinement on the fatigue performance and fracture mechanism of superalloys. In the present research, the IN792 superalloy with different grain sizes was manufactured. Then, fully reversed, strain-controlled, low-cycle fatigue (LCF) tests with four different total strain amplitudes were carried out on the alloy at $700{ }^{\circ} \mathrm{C}$ and $800{ }^{\circ} \mathrm{C}$ to clarify the effects of grain refinement on its LCF behavior. The results show that grain refinement improved the fatigue life significantly, which is mainly attributed to increasing the grain boundary content and refining MC carbides, eutectic structures and dendritic structures. During fatigue test under lower strain amplitude, the alloy exhibits a pronounced initial fatigue hardening followed by a continuous well-defined stability stage, which is caused by the formation of dislocation networks and coarsening of primary $\gamma^{\prime}$ phases. However, during fatigue test under higher strain amplitude, the alloy exhibits continuous hardening response because the dislocations could shear primary $\gamma^{\prime}$ phases, which could give rise to resistance to dislocation movement. In addition, the fracture surface observation shows that the fatigue fracture mode is mainly affected by the total strain amplitude. Under lower total strain amplitude, the fatigue microcracks mainly initiate at the porosities near the specimen surface, while under higher total strain amplitude, the fatigue microcracks tend to form at the interior of the specimen.

Keywords: Ni-based superalloy; grain refinement; low-cycle fatigue; fracture; dislocation

\section{Introduction}

Ni-based polycrystalline cast superalloys have relatively low manufacturing costs, excellent mechanical properties and microstructure stability in the range of $600-900{ }^{\circ} \mathrm{C}$, and they are widely used in aeroengines, gas turbines and automobiles components [1-4]. It has been regarded that the service performance of polycrystalline superalloys is closely related to their grain size, and the refining of grains is always considered as an effective means to improve the mechanical properties and retard their failure [5-7].

However, extensive studies [8-12] have shown that the influence of grain size on the mechanical properties of superalloys is closely related to the experimental conditions. It is generally believed that $[9,11,13-19]$ with the increase in temperature, the strengthening effect of grain refinement on polycrystalline superalloys gradually decreases, because the grain boundary strength drops faster than grain interior strength as the temperature increases. The authors have investigated the tensile properties of Ni-based K417G superalloys 
with different grain sizes [11], and found that grain refinement could improve the tensile strength but decrease the ductility at $700{ }^{\circ} \mathrm{C}$. At $900^{\circ} \mathrm{C}$, grain refinement has little influence on the tensile strength but would decrease the ductility. Wei [8] manufactured IN713LC superalloys with different grain sizes by adjusting the pouring temperature and the results show that the room temperature yield strength increases along with grain refinement. However, when the grains are refined to $25 \mu \mathrm{m}$, the elongation drops significantly, which may be attributed to the existence of porosities. Moreover, studies [4,16-19] have proved that grain refinement would reduce the creep property of superalloys at high temperature, because the grain boundaries would slide and produce intergranular cracks. The creep performance of $\mathrm{K} 417 \mathrm{G}$ superalloys with different grain sizes is also studied by the authors of [20], who found that with the refining of grains, the creep life is improved under $760{ }^{\circ} \mathrm{C} / 645 \mathrm{MPa}$. The creep life under $900^{\circ} \mathrm{C} / 315 \mathrm{MPa}$ first increases and then decreases, while the creep life under $950{ }^{\circ} \mathrm{C} / 235 \mathrm{MPa}$ continuously decreases.

Aeroengine components often suffer from fatigue damages, including high-cycle fatigue (HCF) and low-cycle fatigue (LCF). Kobayashi [21] has investigated the influence of grain size on the HCF properties of an IN718 superalloy, and found that the HCF strength of fine-grain alloys is higher than coarse-grain alloys beyond $10^{5}$ cycles. The research of Chan [22] reveals that HCF crack initiation is favored in coarse-grained alloy compared to fine-grained alloys. The previous investigation of the authors of [10] on the HCF behavior of an IN792 superalloy found that through grain refinement, the "fatigue hot spots" would tend to transfer from specimen subsurface to the center gradually, and the initiation and propagation of fatigue cracks would be impeded. In addition, during the start and stop process of the aeroengine, the components would bear cyclic stress with high stress amplitude and low loading frequency, causing LCF fracture. Morrison [12] has conducted LCF tests on polycrystalline nickel of two grain sizes, and found that the alloy with a fine grain has a longer fatigue life, especially at low strain amplitude, because the refining of grains changed the crack initiation characteristics. Consequently, it can be found that the effect of grain refinement on the fatigue performance and fatigue fracture mechanism of superalloys is closely related to the alloy composition, microstructure, experimental conditions and other factors, and the existing studies have not obtained unified conclusions. Based on our previous research on the HCF properties of IN792 superalloys, in order to clarify the effects of grain refinement on the LCF performance of an IN792 superalloy, different melting and pouring temperatures are applied to this alloy to obtain different grain sizes, and then the microstructures are characterized and LCF tests at different temperatures and total strain amplitudes are conducted. The LCF fracture mode and deformation mechanism are analyzed, and the effects of grain refinement on the LCF performance of IN792 superalloy are discussed.

\section{Materials and Methods}

\subsection{IN792 Superalloy Preparation}

An IN792 superalloy, the nominal composition of which is shown in Table 1, was melted in a vacuum induction furnace. The alloy melt was poured into the mold, which was preheated at $850^{\circ} \mathrm{C}$. As it is known that grain refinement could be achieved by reducing the melting and pouring temperature, two different casting parameters were used to obtain two different grain sizes. The first casting parameters adopt a melting temperature of $1540{ }^{\circ} \mathrm{C}$ and a pouring temperature of $1480^{\circ} \mathrm{C}$ to obtain a coarse-grain alloy, and the secondary casting parameters adopt a melting temperature of $1510^{\circ} \mathrm{C}$ and a pouring temperature of $1360^{\circ} \mathrm{C}$ to obtain a fine-grain alloy. Then, LCF bars of IN792 superalloy with two different grain sizes was acquired. After that, these fatigue bars were heat treated according to the following procedure: $1120^{\circ} \mathrm{C} / 2 \mathrm{~h} \mathrm{AC}+1080^{\circ} \mathrm{C} / 4 \mathrm{~h} \mathrm{AC}+845^{\circ} \mathrm{C} / 24 \mathrm{~h} \mathrm{AC}$. (AC: air cooling.) 
Table 1. Nominal composition of IN792 superalloy (wt. \%).

\begin{tabular}{ccccccccccc}
\hline C & Cr & Co & Mo & W & Ta & Al & Ti & B & Zr & Ni \\
\hline 0.089 & 12.60 & 8.99 & 1.97 & 3.98 & 4.25 & 3.43 & 3.92 & 0.014 & 0.030 & Balance \\
\hline
\end{tabular}

\subsection{Microstructure Observation}

A cylindrical specimen was cut from the heat-treated fatigue bars, and then mechani-

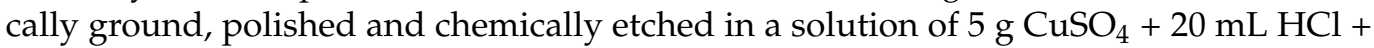
$25 \mathrm{~mL} \mathrm{H}_{2} \mathrm{O}$ for microstructure observation. The microstructures of the IN792 superalloy, including grain size and precipitates, were observed through optical microscope (OM) and S3400N scanning electron microscope (SEM). An Image-Pro Plus (IPP) software was used to measure the volume fraction and average size of the grains and precipitates. The casting defects were observed through OM. Thin slices were cut for $\gamma^{\prime}$ phase observation on transmission electron microscope (TEM). The slices were first mechanically ground to $50 \mu \mathrm{m}$ thick, then twin-jet thinned in a solution of $10 \%$ perchloric acid and $90 \%$ alcohol at $-20{ }^{\circ} \mathrm{C}$; the twin-jet current is maintained at $40 \mathrm{~mA}$. TEM observation was performed on JEM2100.

\subsection{LCF Tests}

The heat-treated bars were machined into standard LCF specimens, as shown in Figure 1. The LCF tests were conducted on a PLG-100C testing machine. All the specimens were tested under strain control at a strain ratio $\mathrm{R}=E_{\min } / E_{\max }=-1$. The testing temperatures were $700{ }^{\circ} \mathrm{C}$ and $800{ }^{\circ} \mathrm{C}$. A tensile-compressive loading mode was adopted and sinusoidal waveform was performed on the specimens. Four different total strain amplitudes $\left(\Delta E_{\mathrm{t}}\right), 0.4 \%, 0.5 \%, 0.6 \%$ and $0.8 \%$, were used for each temperature.

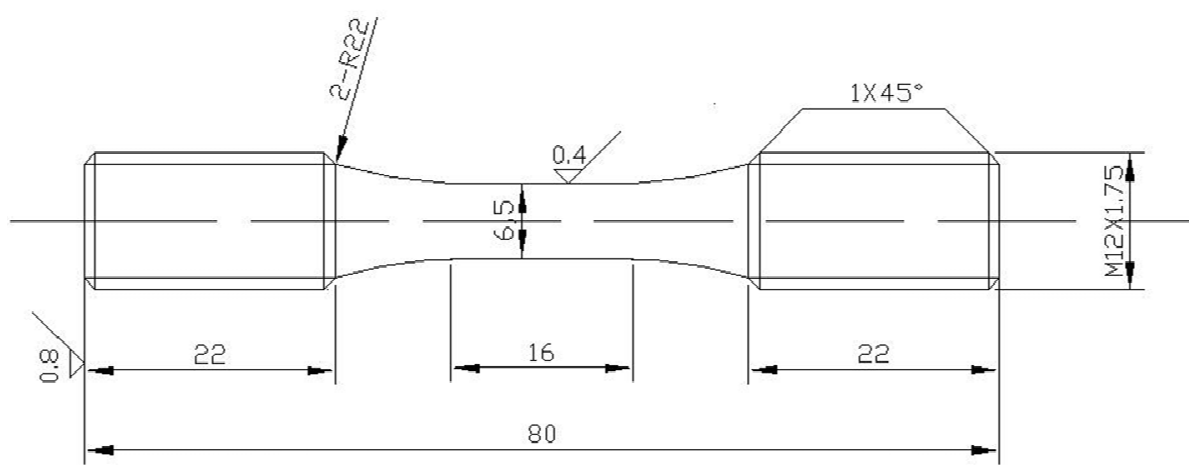

Figure 1. Standard LCF specimen.

\subsection{Fractured Specimen Observation}

After LCF tests, the fracture surfaces were examined on SEM to analyze the fracture mode. Longitudinal section samples were cut from the fractured specimens and mounted in epoxy resin. After grinding, polishing and chemical etching, the longitudinal sections were observed on SEM to study the microstructure evolution and deformation mechanism of the superalloy. In addition, TEM observation was conducted on the fatigue fractured specimens to analyze the crystal defects. Samples for TEM observation were obtained from thin slices cut at a distance of $5 \mathrm{~mm}$ away from the fracture surfaces of the failed specimens. Thin slices were prepared by twin-jet thinning electrolytically in a solution of $10 \%$ perchloric acid and $90 \%$ alcohol at $-20{ }^{\circ} \mathrm{C}, 40 \mathrm{~mA}$. TEM observation was performed on JEM2100. 


\section{Results \\ 3.1. Microstructure}

The microstructures of the IN792 superalloys with two different grain sizes are characterized through OM and SEM, as shown in Figure 2. The average sizes of the grains and precipitates were calculated and are shown in Table 2. The coarse-grain alloy is named CG, and the fine-grain alloy is named FG. It can be found that both the CG and FG superalloys are composed of equiaxed grains with dendritic structure inside the grains. The average grain size of the CG alloys is calculated to be about $2.3 \mathrm{~mm}$, while the average grain size of the FG alloys is about $0.4 \mathrm{~mm}$. The dendritic structure of the FG alloy is also finer than that of CG alloy, as illustrated in Figure 2a,e. Block and strip MC carbides precipitate in the interdendritic regions and at the grain boundary, as indicated in Figure 2b,f. According to measurements, the average sizes of MC carbides of the CG alloy and the FG alloy are $2.6 \mu \mathrm{m}$ and $1.9 \mu \mathrm{m}$, respectively. In addition, flower-like $\gamma / \gamma^{\prime}$ eutectic structures formed in the interdendritic regions and at the grain boundary of IN792 superalloys, as in Figure 2c,g. The average sizes of the $\gamma / \gamma^{\prime}$ eutectic structures of CG alloy and FG alloy are $10.7 \mu \mathrm{m}$ and $8.1 \mu \mathrm{m}$. In conclusion, the grain refinement has refined the dendritic structures, MC carbides and $\gamma / \gamma^{\prime}$ eutectic structures of IN792 superalloy. In addition, our previous studies [23-25] found $\mathrm{M}_{5} \mathrm{~B}_{3}$ borides at the grain boundary of IN792 superalloys. In the present research, fine granular borides of about 1 to 2 microns disperse at the grain boundary of CG and FG alloys, as shown in Figure 2d,h, and there is no difference between the grain boundary $\mathrm{M}_{5} \mathrm{~B}_{3}$ borides of $\mathrm{CG}$ and $\mathrm{FG}$ alloys.
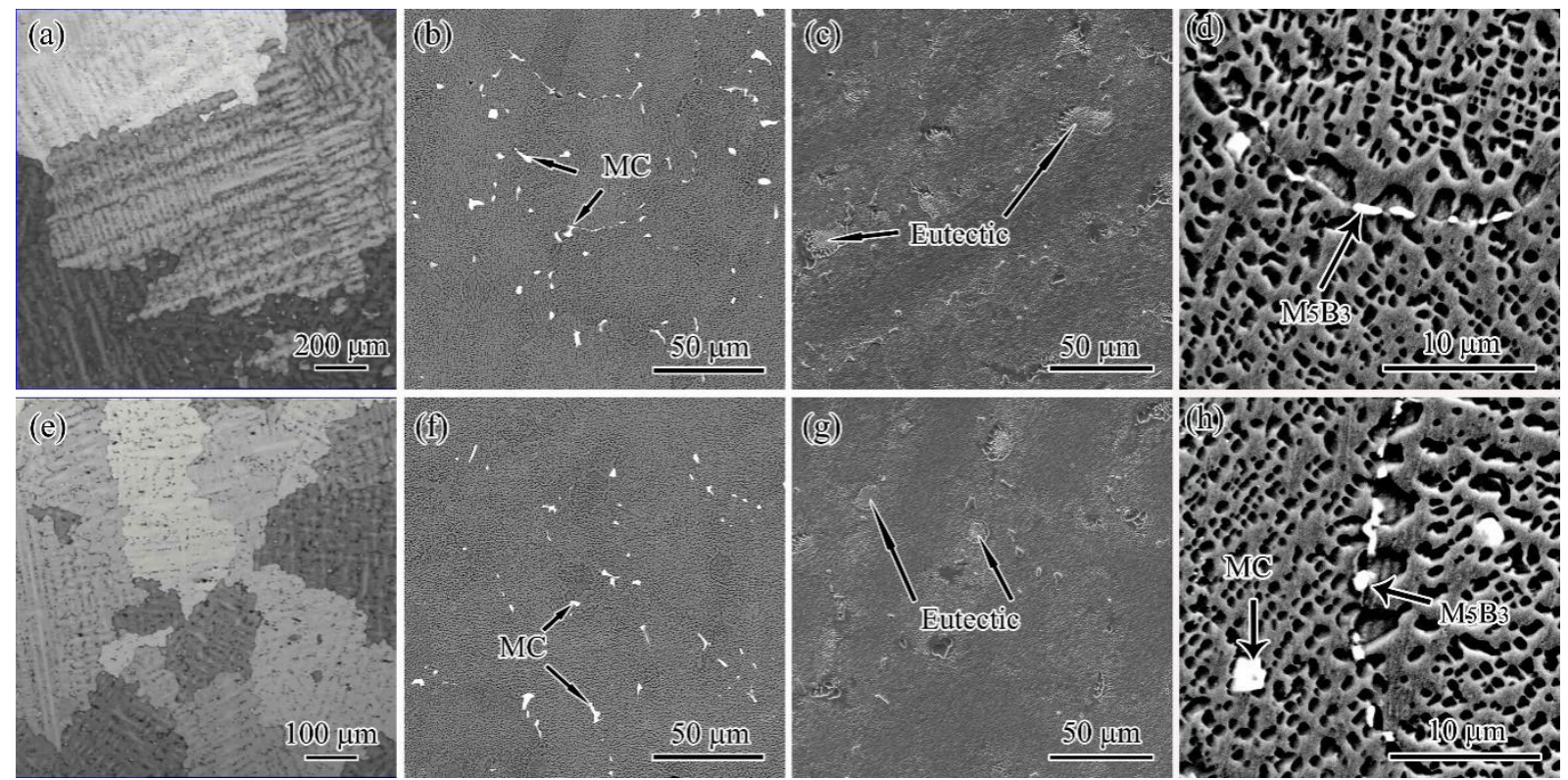

Figure 2. Microstructure of IN792 superalloys with two different grain sizes. (a) OM image of grain morphology of the CG superalloy. (b) Backscatter electron image of MC carbides of the CG superalloy. (c) Secondary electron image of eutectic structures of the CG superalloys. (d) Backscatter electron image of grain boundary $\mathrm{M}_{5} \mathrm{~B}_{3}$ borides of the CG superalloy. (e) OM image of grain morphology of the FG superalloy. (f) Backscatter electron image of MC carbides of the FG superalloy. (g) Secondary electron image of eutectic structures of the FG superalloys. (h) Backscatter electron image of grain boundary $\mathrm{M}_{5} \mathrm{~B}_{3}$ borides of the FG superalloy. 
Table 2. The average size of the grain, $\gamma^{\prime}$ phase, carbide and eutectic of coarse- and fine-grain specimens.

\begin{tabular}{ccccc}
\hline & $\begin{array}{c}\text { Average Grain } \\
\text { Size }(\mu \mathrm{m})\end{array}$ & $\begin{array}{c}\text { Average Size of MC } \\
\text { Carbide }(\mu \mathrm{m})\end{array}$ & $\begin{array}{c}\text { Average Size of } \\
\text { Eutectic }(\mu \mathrm{m})\end{array}$ & $\begin{array}{c}\text { Average Size of } \boldsymbol{\gamma}^{\prime} \text { Phase } \\
\text { in the Dendrite Core }(\mathbf{n m})\end{array}$ \\
\hline CG & 2300 & 2.6 & 10.7 & 430 \\
FG & 400 & 1.9 & 8.1 & 420 \\
\hline
\end{tabular}

It is known that $\gamma^{\prime}$ phase is the main strengthening phase of Ni-based superalloy. The $\gamma^{\prime}$ phase of IN792 superalloys is observed through SEM and TEM, as shown in Figure 3. The primary $\gamma^{\prime}$ phase is regular cuboidal shaped with an average size of about $400 \mathrm{~nm}$, as can be found from Figure 3a,c and Table 2. Therefore, the $\gamma^{\prime}$ phase is not refined by grain refinement. In the TEM bright-field images, granular secondary $\gamma^{\prime}$ phases are found around primary $\gamma^{\prime}$ phases. These secondary $\gamma^{\prime}$ phases are about $60 \mathrm{~nm}$ for both the CG and FG alloys, as exhibited in Figure 3b,d.
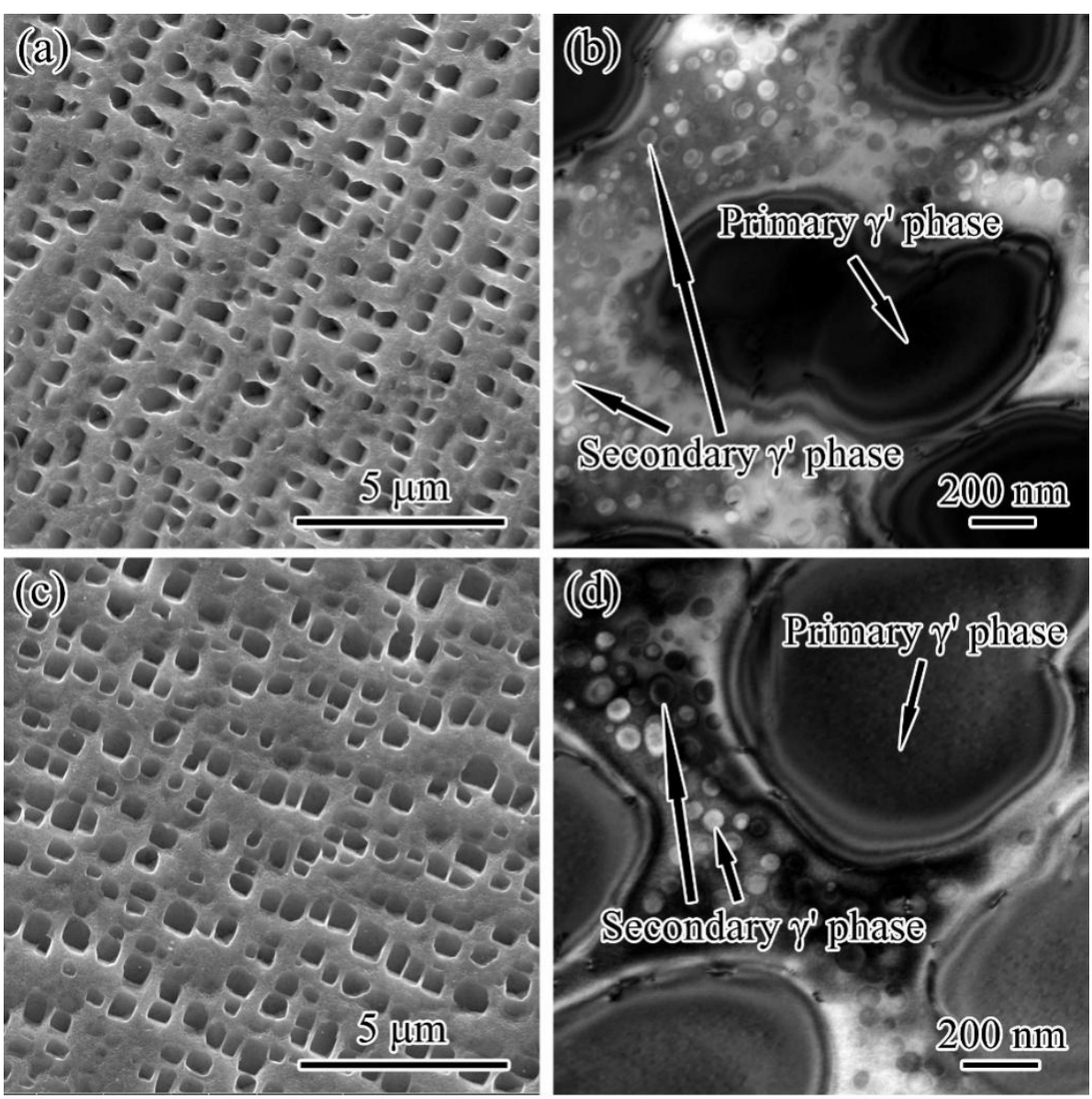

Figure 3. The $\gamma^{\prime}$ phases of CG and FG IN792 superalloys: (a) SEM image of $\gamma^{\prime}$ phases of CG alloy; (b) TEM bright-field image of $\gamma^{\prime}$ phases of CG alloy; (c) SEM image of $\gamma^{\prime}$ phases of FG alloy; (d) TEM bright-field image of $\gamma^{\prime}$ phases of FG alloy.

The casting defects such as porosities are inevitable in cast superalloys, which would influence the mechanical properties, especially the fatigue property. It has been reported $[10,26,27]$ that the casting defects could act as fatigue crack initiation sites, thus leading to the fracture of superalloys. The casting defects of IN792 superalloys in the present study are observed through OM, and it can be found that granular porosities about 10 to $30 \mu \mathrm{m}$ are dispersed in the areas near the specimen surface for both grain size alloys, as shown in Figure $4 \mathrm{a}, \mathrm{c}$. In the center areas of the specimen, however, there are some 
irregular-shaped porosities gathering areas, as shown in Figure $4 \mathrm{~b}$, d. This is because the center of the specimen is the final solidification area, and the mobility of the melt is poor at this time; thus, the porosity formation tendency is higher than the edge area. These irregular-shaped porosities gathering areas in FG alloys are larger than that in CG alloys, which is because of the low pouring temperature.
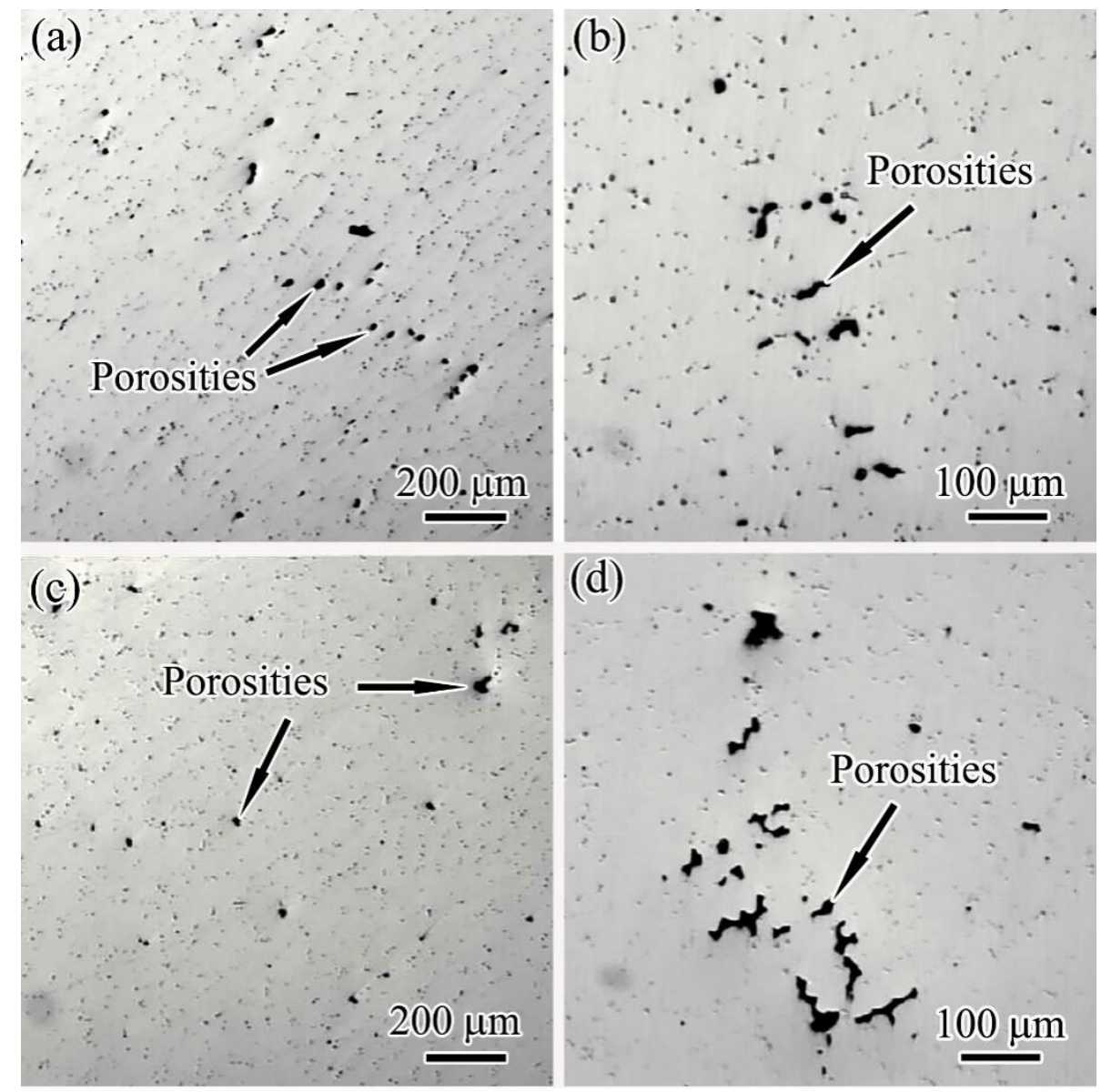

Figure 4. Casting defects of IN792 superalloys. (a) Porosities near the specimen surface of CG alloy. (b) Porosities in the specimen center of CG alloy. (c) Porosities near the specimen surface of FG alloy. (d) Porosities in the specimen center of FG alloy.

\subsection{Cyclic Stress Response Behavior}

The LCF properties of IN792 superalloys with different grain sizes were tested at $700{ }^{\circ} \mathrm{C}$ and $800{ }^{\circ} \mathrm{C}$, and four different total strain amplitudes $(\Delta E \mathrm{t}), 0.004,0.005,0.006$ and 0.008 , were applied. The cyclic stress response behaviors are shown in Figure 5 . When the total strain amplitude is 0.004 , the IN792 superalloys show an obvious cyclic hardening response soon after several cycles of loading. Until after dozens of cycles, the cyclic hardening response ends, and the alloys gradually present a cyclic stability, as illustrated in Figure 5a. The cyclic hardening content at $700{ }^{\circ} \mathrm{C}$ is higher than $800{ }^{\circ} \mathrm{C}$. Moreover, the stress amplitude of the FG alloy is always higher than the CG alloy. When the total strain amplitude is 0.005 , the stress response shows a similar tendency with the total strain amplitude of 0.004 , except for a cyclic softening at the final stage of fatigue, especially for the CG alloys, as can be found from Figure 5b. As the total strain amplitude increases to 0.006 , the IN792 superalloys show continuous cyclic hardening response during the whole fatigue process. When the total strain amplitude is 0.008 , the IN792 superalloys show continuous cyclic hardening response at $700{ }^{\circ} \mathrm{C}$, but when these alloys are fatigue tested under $800^{\circ} \mathrm{C}$, there is a short steady stage at the end of the fatigue test, as indicated in Figure 5d. 


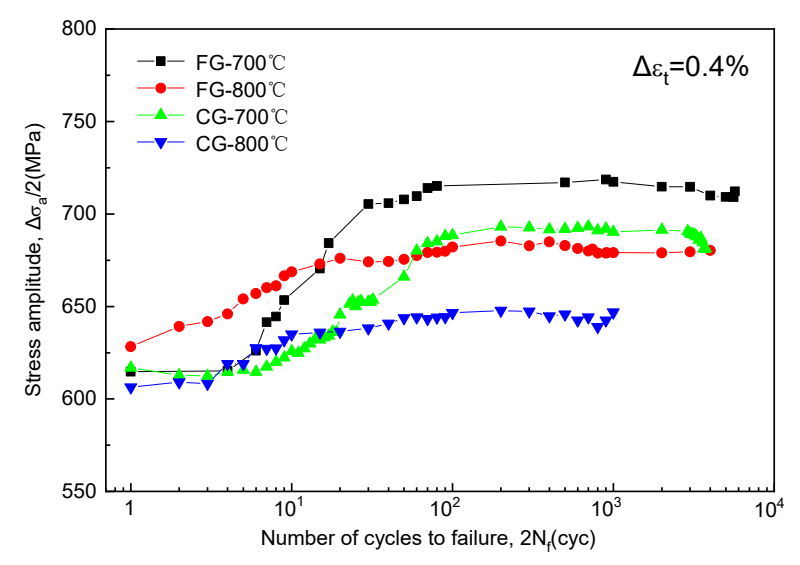

(a)

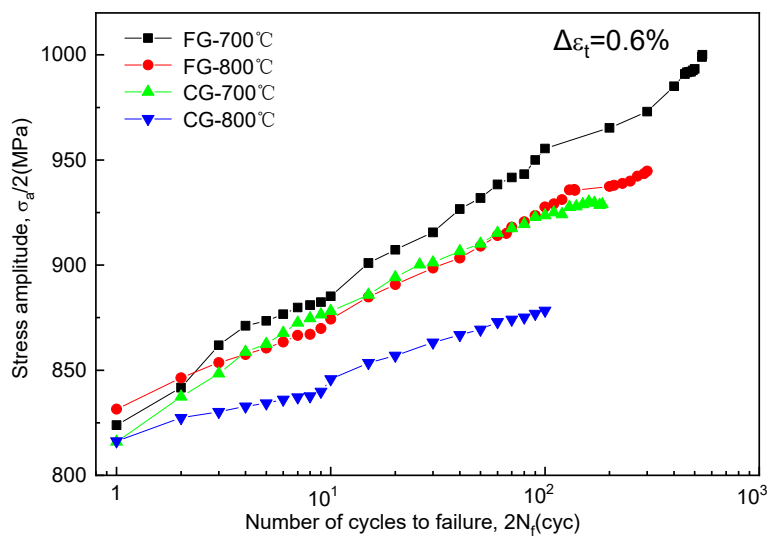

(c)

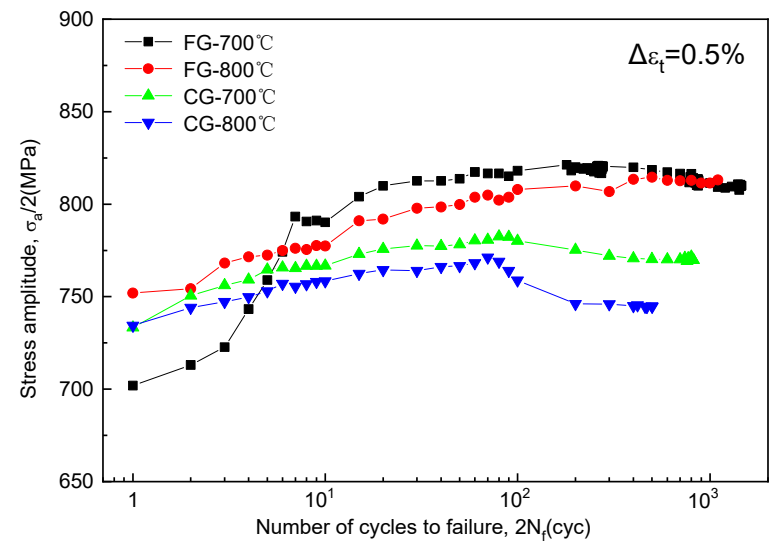

(b)

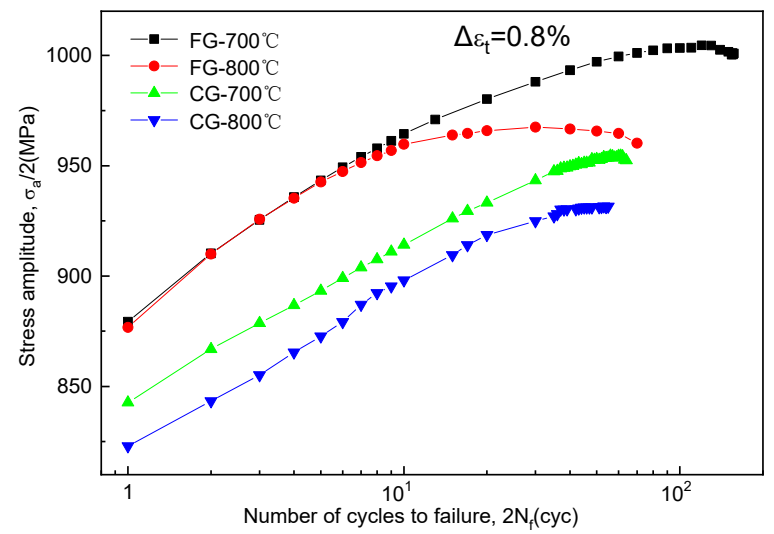

(d)

Figure 5. Cyclic stress response curves of IN792 superalloys: (a) $\Delta E \mathrm{t}=0.4 \%$; (b) $\Delta E \mathrm{t}=0.5 \% ;(\mathbf{c}) \Delta E \mathrm{t}=0.6 \% ;(\mathbf{d}) \Delta E \mathrm{t}=0.8 \%$.

\subsection{Fatigue Life Curves}

The relationship curves between total strain amplitudes and number of cycles to failure are plotted in Figure 6. It can be found that the fatigue life decreases with the increase in total strain amplitude. The fatigue life of the FG alloy is higher than the CG alloy at the same total strain amplitude.

The strain-controlled low-cycle fatigue performance of superalloys is generally described by the Coffin-Manson relationship, which separates the total strain amplitude into plastic and elastic strain amplitude, expressed as follows [28]:

$$
\frac{\Delta \varepsilon_{t}}{2}=\frac{\Delta \varepsilon_{p}}{2}+\frac{\Delta \varepsilon_{e}}{2}=\varepsilon_{f}^{\prime}\left(2 N_{f}\right)^{-c}+\frac{\sigma_{f}^{\prime}}{E}\left(2 N_{f}\right)^{-b}
$$

where $\frac{\Delta \varepsilon_{t}}{2}$ is total strain amplitude, $\frac{\Delta \varepsilon_{p}}{2}$ is plastic strain amplitude, $\frac{\Delta \varepsilon_{e}}{2}$ is elastic strain amplitude, $2 N_{f}$ is the number of cycles to failure, $\varepsilon_{f}^{\prime}$ and $\sigma_{f}^{\prime}$ are the fatigue ductility and fatigue strength coefficients, respectively, and $\mathrm{c}$ and $\mathrm{b}$ are ductility and strength exponents. The fitting curves of the IN792 superalloys with two different grain sizes LCF tested at $700{ }^{\circ} \mathrm{C}$ and $800{ }^{\circ} \mathrm{C}$ are shown in Figure 7, and the parameters in the Coffin-Mansion relationship are indicated in Table 3. It can be found that the grain refinement increased all the parameters when $\mathrm{LCF}$ tested at $700{ }^{\circ} \mathrm{C}$, which means that both the LCF strength and deformation resistance is improved. For LCF tests at $800{ }^{\circ} \mathrm{C}$, the grain refinement increased the fatigue ductility and strength coefficient, but slightly decreased the ductility and strength exponent. Therefore, increasing the temperature weakened the LCF property improvement of IN792 superalloys caused by grain refinement. 


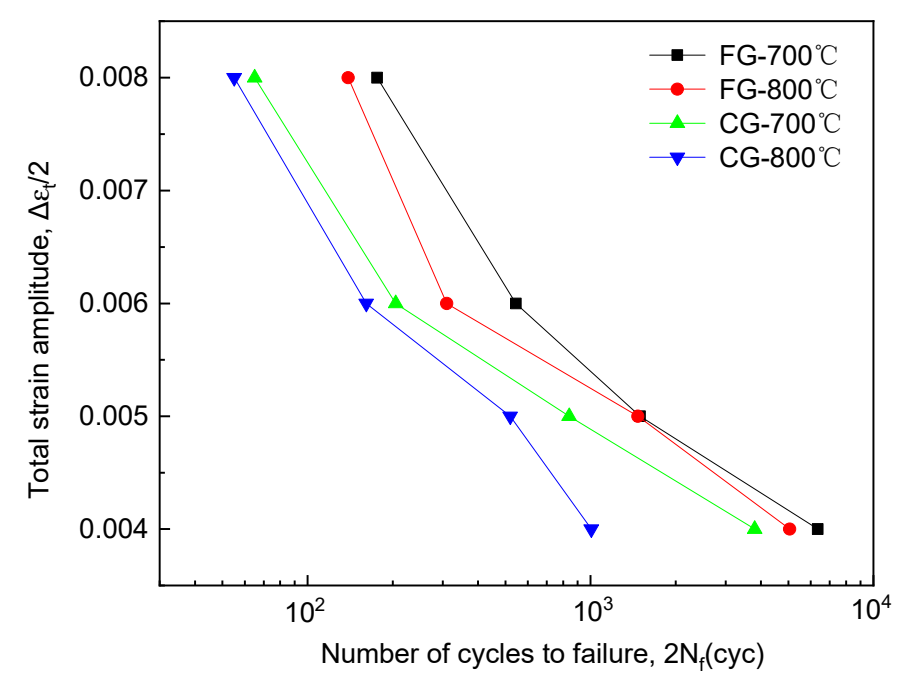

Figure 6. The total strain amplitudes vs. number of cycles to failure curves of IN792 superalloys with different grain sizes under $700{ }^{\circ} \mathrm{C}$ and $800{ }^{\circ} \mathrm{C}$.

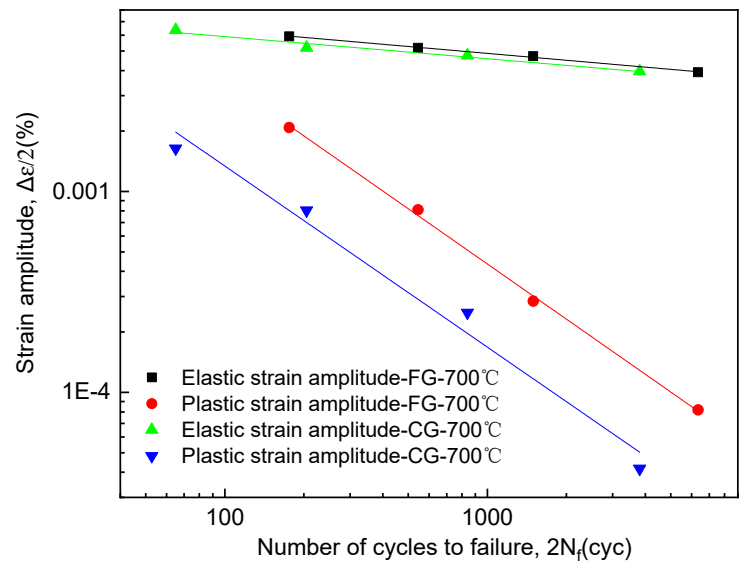

(a)

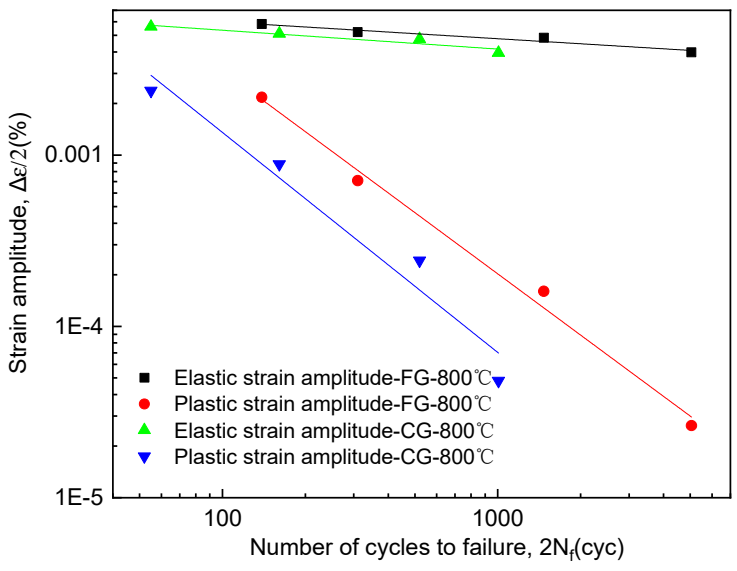

(b)

Figure 7. The Coffin-Mansion relationship fitting curves of IN792 superalloys with different grain sizes: (a) LCF tested at $700{ }^{\circ} \mathrm{C} ;(\mathbf{b}) \mathrm{LCF}$ tested at $800{ }^{\circ} \mathrm{C}$.

Table 3. Parameters in the Coffin-Mansion relationship of IN792 superalloys with different grain sizes under different LCF temperatures.

\begin{tabular}{ccccc}
\hline & $\sigma_{f}^{\prime}$ & $\mathbf{b}$ & $\boldsymbol{\varepsilon}_{f}^{\prime}$ & $\mathbf{c}$ \\
\hline $\mathrm{FG}-700{ }^{\circ} \mathrm{C}$ & 1710 & 0.114 & 0.238 & 0.912 \\
$\mathrm{CG}-700^{\circ} \mathrm{C}$ & 1568 & 0.110 & 0.085 & 0.901 \\
$\mathrm{FG}-800^{\circ} \mathrm{C}$ & 1524 & 0.099 & 0.742 & 1.188 \\
$\mathrm{CG}-800^{\circ} \mathrm{C}$ & 1423 & 0.110 & 0.503 & 1.285 \\
\hline
\end{tabular}

The surface of the LCF fractured specimens were observed through SEM and the results are shown in Figure 8. Basically, two different fracture modes are found for the IN792 superalloys in the present study, and the fracture mode changes with the applied total strain amplitude. When the total strain amplitude is low, such as 0.004 or 0.005 , the fatigue crack mainly initiates from the porosities near the specimen surface, and then propagate towards the specimen interior transgranularly, as shown in Figure 8a,b,e and 8f. The crack extension path is flat and perpendicular to the cyclic stress direction, and the 
river-like patterns exhibit the expansion direction of the crack. According to our previous study [10], the porosities near the sample surface are more likely to incubate a crack under HCF load. Therefore, the LCF fracture mode of IN792 superalloys at a low total strain amplitude is similar to HCF fracture. Meanwhile, when the total strain amplitude is high, such as 0.006 or 0.008 , the fatigue life is rather short, and the fatigue crack are more likely to produce in the center of the specimen and then expand around transgranularly. The crack extension path is rough with obvious dendritic characteristics, indicating that the crack expands along the interdendritic region. The LCF fracture mode of IN792 superalloys at a high total strain amplitude is similar to the tensile fracture mode, as demonstrated in our previous study of the tensile properties of IN792 superalloys [29].
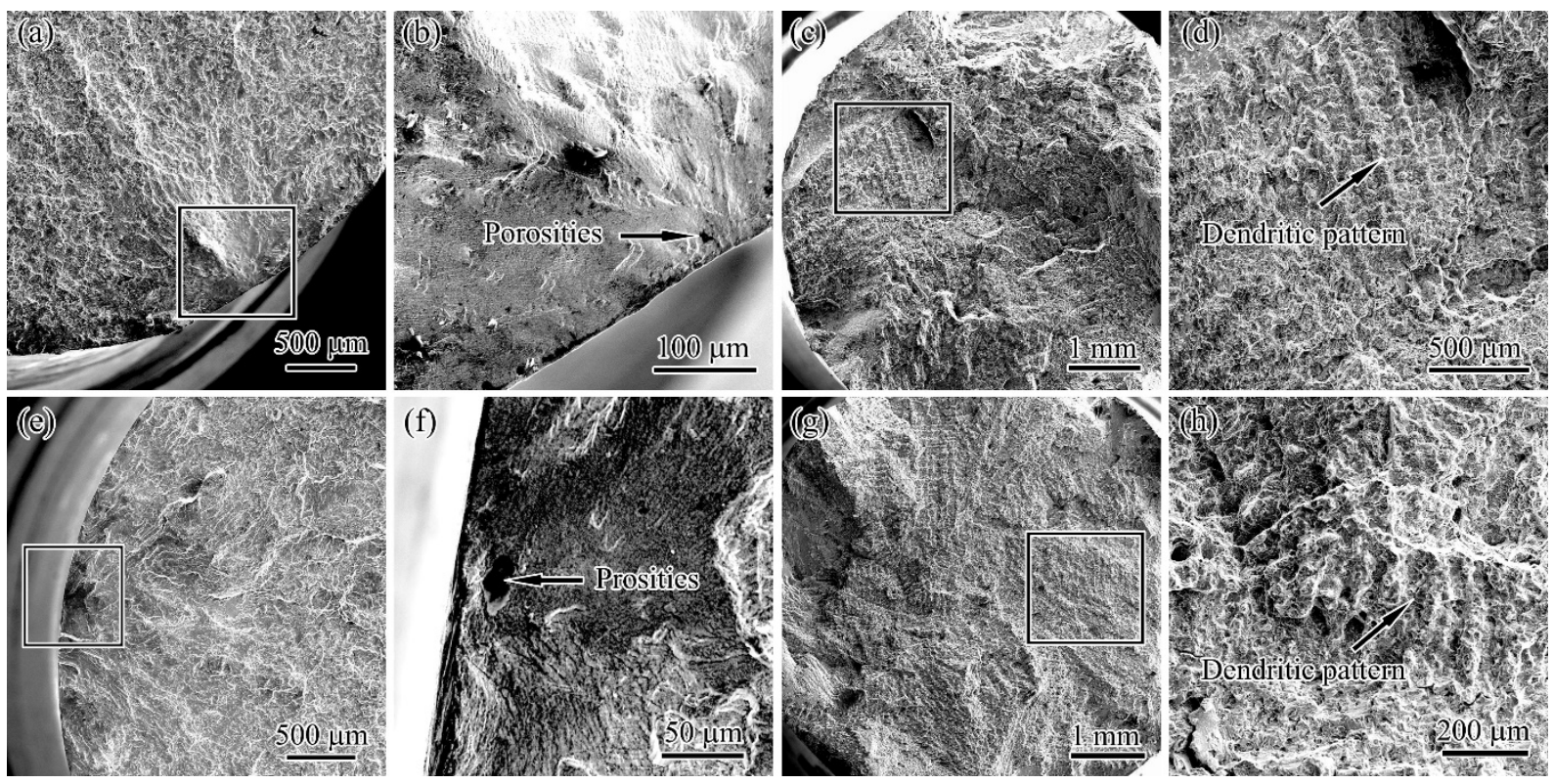

Figure 8. The LCF fracture morphology of IN792 superalloys under different total strain amplitudes and testing temperature (the parts in box in $(\mathbf{a}, \mathbf{c}, \mathbf{e}, \mathbf{g})$ are enlarged and displayed in (b,d,f,h), respectively.): (a,b) FG alloy tested at $700{ }^{\circ} \mathrm{C}$, $\Delta E \mathrm{t}=0.4 \%$, the fatigue life is $6348 ;(\mathbf{c}, \mathbf{d}) \mathrm{CG}$ alloy tested at $700{ }^{\circ} \mathrm{C}, \Delta E \mathrm{t}=0.8 \%$, the fatigue life is $65 ;(\mathbf{e}, \mathbf{f}) \mathrm{FG}$ alloy tested at $800{ }^{\circ} \mathrm{C}, \Delta E \mathrm{t}=0.4 \%$, the fatigue life is $5054 ;(\mathrm{g}, \mathrm{h}) \mathrm{CG}$ alloy tested at $800{ }^{\circ} \mathrm{C}, \Delta E \mathrm{t}=0.6 \%$, the fatigue life is 161.

\subsection{Microstructure of Fractured Specimens}

After LCF tests, the fractured specimens were cut up along the longitudinal section, and the microstructures near the fracture surface were observed through SEM. It was found that the when the total strain amplitude is low, the specimen bears relatively low cyclic stress, the MC carbides would not break and produce cracks and the grain boundaries would not crack whether LCF tested at $700^{\circ} \mathrm{C}$ or $800^{\circ} \mathrm{C}$, as shown in Figure 9 a,d. However, when the total strain amplitude is high, the cyclic stress that the specimen bears is high; thus, the MC carbides would break and become crack initiate sites, as indicated in Figure $9 \mathrm{~b}$,e. The grain boundary $\mathrm{M}_{5} \mathrm{~B}_{3}$ borides maintain a fine granular shape, and no obvious differences are found compared from the before tests, regardless of the testing temperature and applied total strain amplitude in the present study, as in Figure 9c,f. Therefore, the $\mathrm{M}_{5} \mathrm{~B}_{3}$ borides could play a grain boundary pinning role during LCF tests under $700{ }^{\circ} \mathrm{C}$ and $800{ }^{\circ} \mathrm{C}$, which would hinder the grain boundary cracking. As a result, the grain boundary could keep good structure stability and high strength during LCF tests at $700{ }^{\circ} \mathrm{C}$ and $800^{\circ} \mathrm{C}$. As a result, the increase in grain boundary content through grain refinement could improve the LCF property of this superalloy. 

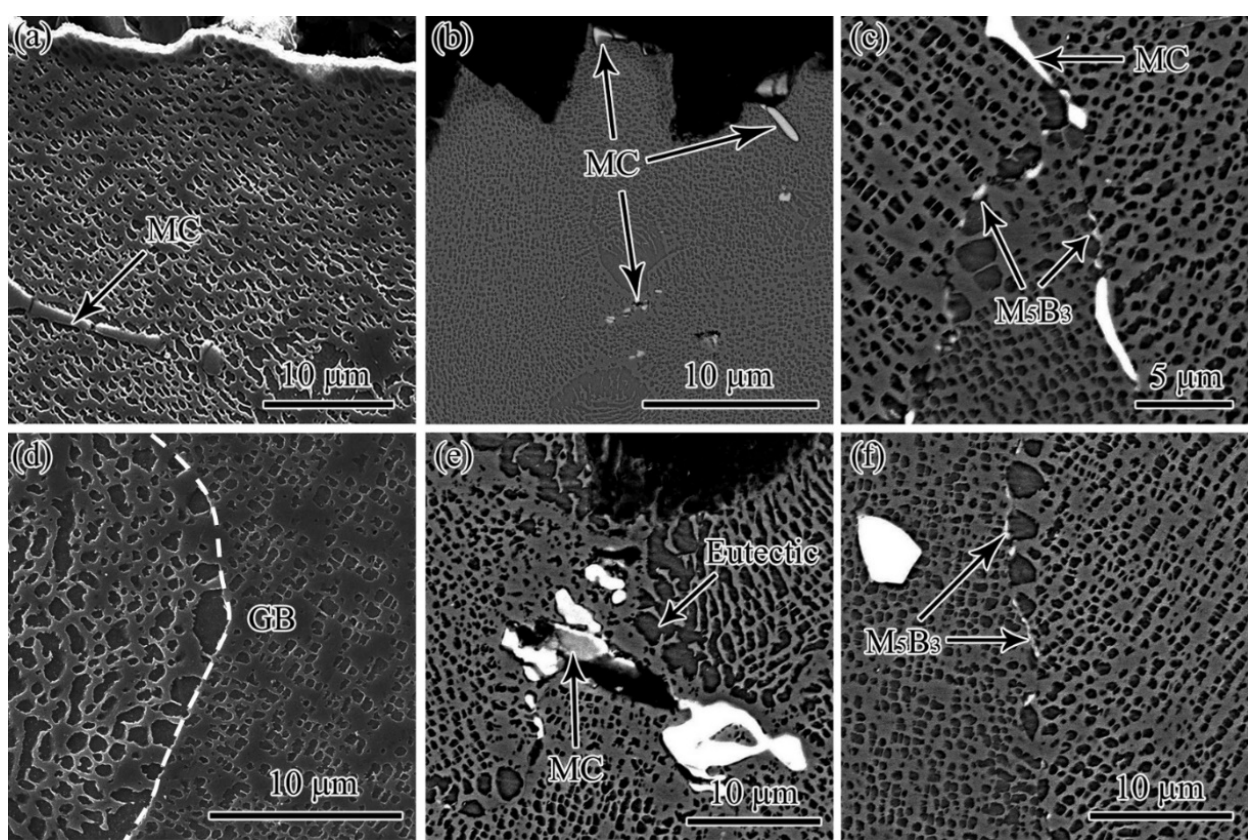

Figure 9. The microstructure of the LCF fractured IN792 superalloy near the fracture surface: (a) Secondary electron image of $\mathrm{CG}$ alloy tested at $700{ }^{\circ} \mathrm{C}, \Delta E_{\mathrm{t}}=0.5 \%$. (b) Backscatter electron image of CG alloy tested at $700{ }^{\circ} \mathrm{C}, \Delta E_{\mathrm{t}}=0.8 \%$. (c) Backscatter electron image of $\mathrm{CG}$ alloy tested at $700{ }^{\circ} \mathrm{C}, \Delta E_{\mathrm{t}}=0.4 \%$. (d) Secondary electron image of CG alloy tested at $800{ }^{\circ} \mathrm{C}, \Delta E_{\mathrm{t}}=0.4 \%$. (e) Backscatter electron image of $\mathrm{CG}$ alloy tested at $800{ }^{\circ} \mathrm{C}, \Delta E_{\mathrm{t}}=0.8 \%$. (f) Backscatter electron image of $\mathrm{CG}$ alloy tested at $800{ }^{\circ} \mathrm{C}, \Delta E_{\mathrm{t}}=0.6 \%$.

As the main strengthening phase of superalloy, $\gamma^{\prime}$ phase would evolve during service of superalloy under high temperature, which could affect the deformation resistance of superalloy. The average size of primary $\gamma^{\prime}$ phase after LCF tests under different conditions is measured through the area method, and the results are shown in Figure 10. It can be found that the $\gamma^{\prime}$ phase would grow larger gradually during LCF tests, and the lower the total strain amplitude, the longer the fatigue life and the larger the $\gamma^{\prime}$ phase size after LCF tests. Comparing Figure 10a,b, there is no significant difference in the size evolution of $\gamma^{\prime}$ phase of FG alloy and CG alloy during LCF tests. Moreover, as the testing temperature rises from $700{ }^{\circ} \mathrm{C}$ to $800{ }^{\circ} \mathrm{C}$, the $\gamma^{\prime}$ phase size after LCF tests would increase slightly.

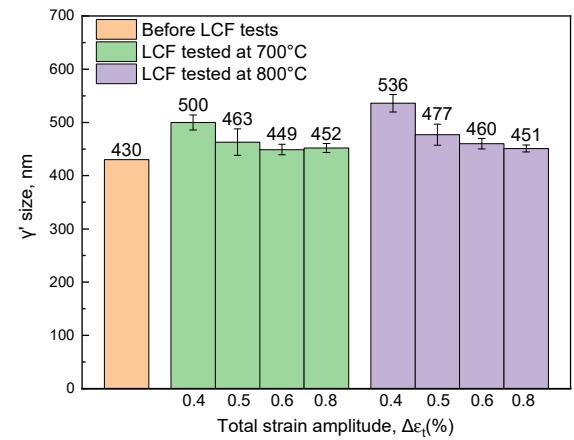

(a)

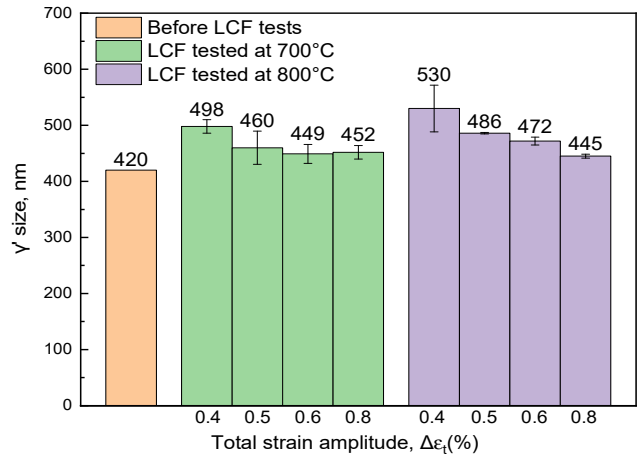

(b)

Figure 10. The average size of $\gamma^{\prime}$ phases of IN792 superalloys before and after LCF tests: (a) CG alloy; (b) FG alloy.

\subsection{Dislocation Structure after LCF Tests}

The dislocation structures of IN792 superalloys after LCF tests were observed through TEM to analyze the deformation mechanism, and the results are revealed in Figure 11. Since the $\gamma^{\prime}$ phases of CG and FG alloys do not show differences, their dislocation structure 
is also the same. When the applied total strain amplitude is relatively low, the stress that the superalloy bears is low. The dislocations could only slip in the $\gamma$ channel between $\gamma^{\prime}$ phases, and no stacking fault was found in $\gamma^{\prime}$ phases, which means that there is not enough shear stress for dislocations to shear the $\gamma^{\prime}$ phases, and the dislocations would accumulate at the interface of $\gamma / \gamma^{\prime}$ phase, thus forming dislocation networks, as indicated in Figure 11a. However, as the applied total strain amplitude increases to 0.006 and 0.008 , stacking faults appear in the primary $\gamma^{\prime}$ phases, as can be seen in Figure 11b, which implies that the $\frac{a}{2}<1 \overline{1} 0>$ dislocations could dissociate at $\gamma / \gamma^{\prime}$ interface, creating two partial dislocations according to the following reaction [30]:

$$
\frac{a}{2}<1 \overline{1} 0>\rightarrow \frac{a}{3}<1 \overline{2} 1>+S I S F+\frac{a}{6}<11 \overline{2}>
$$

where SISF is superlattice intrinsic stacking fault. The $\frac{a}{3}<1 \overline{2} 1>$ partial dislocation could shear the primary $\gamma^{\prime}$ phases, and SISF is left in the primary $\gamma^{\prime}$ phases. Moreover, the dislocations are quite curved because they would bypass the fine secondary $\gamma^{\prime}$ phases through the Orowan mechanism. Some Orowan loops can be found around the secondary $\gamma^{\prime}$ phases, as shown in Figure 11c. When the LCF testing temperature rises to $800{ }^{\circ} \mathrm{C}$, the dislocation structure morphology is similar to that of $700{ }^{\circ} \mathrm{C}$ under low total strain amplitude, and the $\gamma$ channel is filled with dislocation networks, and no stacking fault is formed, as indicated in Figure 11d. Under high total strain amplitude, besides the stacking faults in primary $\gamma^{\prime}$ phases, Orowan loops are also found around the primary $\gamma^{\prime}$ phases, as revealed in Figure 11e. Therefore, the dislocations would interact with the primary $\gamma^{\prime}$ phases through two ways: shearing and Orowan bypass mechanism when the LCF testing temperature is $800{ }^{\circ} \mathrm{C}$ and the total strain amplitude is relatively high. In addition, for the fine secondary $\gamma^{\prime}$ phases, the dislocations would also bypass them through Orowan mechanism, as indicated in Figure 11f.
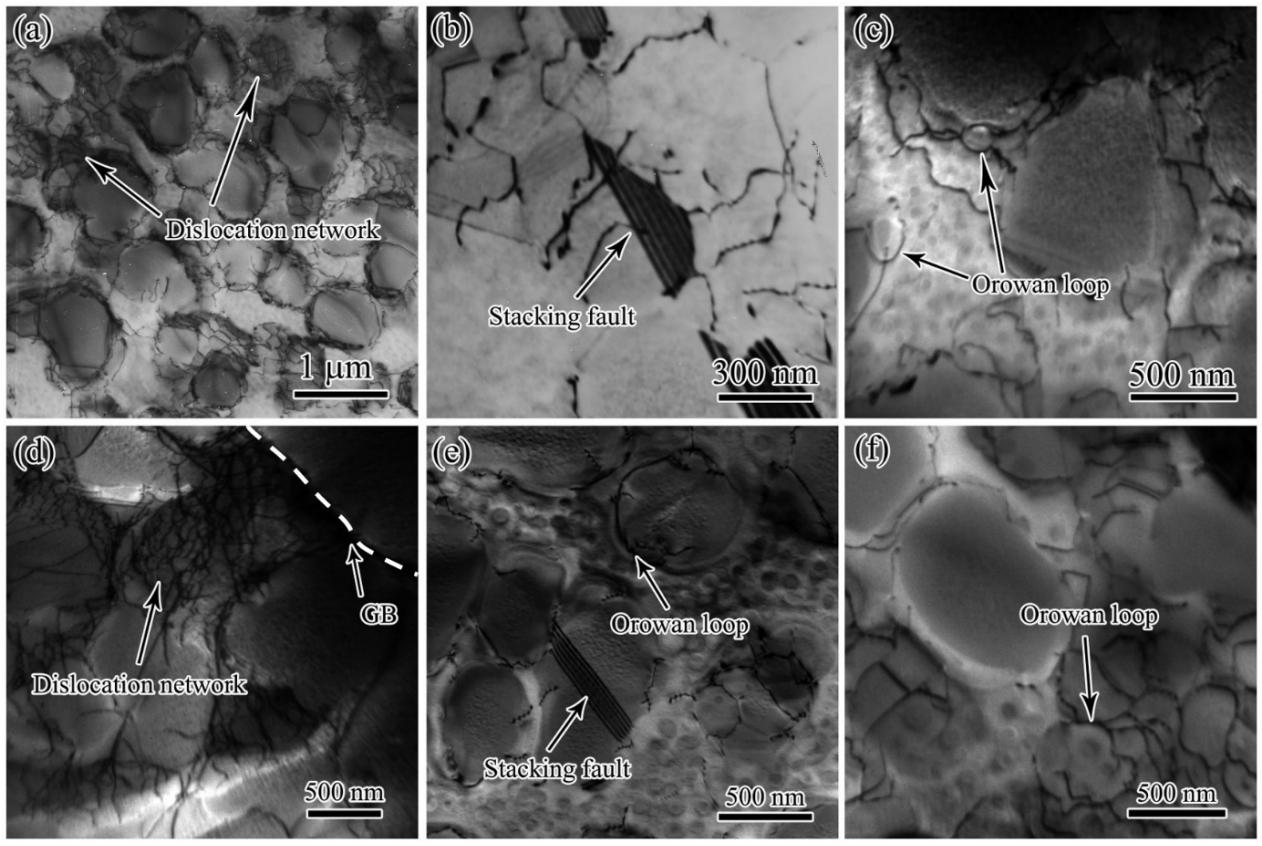

Figure 11. Dislocation structures of IN792 superalloys after LCF tests under different conditions: (a) FG alloy tested at $700{ }^{\circ} \mathrm{C}, \Delta E_{\mathrm{t}}=0.5 \%$; (b) CG alloy tested at $700{ }^{\circ} \mathrm{C}, \Delta E_{\mathrm{t}}=0.8 \%$; (c) FG alloy tested at $700{ }^{\circ} \mathrm{C}, \Delta E_{\mathrm{t}}=0.6 \%$; (d) FG alloy tested at $800{ }^{\circ} \mathrm{C}, \Delta E_{\mathrm{t}}=0.4 \%$; (e) FG alloy tested at $800{ }^{\circ} \mathrm{C}, \Delta E_{\mathrm{t}}=0.6 \%$; (f) CG alloy tested at $800{ }^{\circ} \mathrm{C}, \Delta E_{\mathrm{t}}=0.5 \%$. 


\section{Discussion}

\subsection{The Cyclic Stress Response Behavior of IN792 Superalloy}

The cyclic stress response behavior is always explained by the dislocation movement and interaction between dislocations and precipitates [31-34]. It is generally believed that at the beginning of fatigue loading, dislocations start to multiply, and the precipitates would block the dislocation movement, thus causing cyclic hardening. Under a low total strain amplitude, the above analysis has shown that a large number of dislocation networks are formed in the interface of $\gamma / \gamma^{\prime}$ phases, which would decrease the coherence of the interface and result in fatigue softening. Moreover, when the total strain amplitude is low, the fatigue life is long, and the primary $\gamma^{\prime}$ phases grow large after LCF tests, as shown in Figure 10. It has been reported [33] that the coarsening of $\gamma^{\prime}$ phases would cause a reduction in coherent interfaces, thus lead to a softening behavior. As a result, the softening effects brought by dislocation networks and coarsening of primary $\gamma^{\prime}$ phases would counteract the hardening effect, thus creating a stable stress response behavior after dozens of loading cycles, as illustrated in Figure 5a,b. In addition, there are a lot of dislocations that accumulate at the grain boundary, as in Figure 11d, which proved that the grain boundary could block dislocation movement $[9,35,36]$. The grain refinement increased the grain boundary content of the IN792 superalloy and brought greater hindrance to the dislocation movement, and therefore, the stress amplitude of FG alloys is higher than CG alloys, as demonstrated in Figure 5.

When the total strain amplitude increases to 0.006 , the dislocation could shear primary $\gamma^{\prime}$ phases, as exhibited in Figure $11 \mathrm{~b}$,e. The shearing of $\gamma^{\prime}$ phases could lead to resistance to dislocation movement, thus increasing the stress amplitude during LCF tests. Therefore, the IN792 superalloys show a continuous cyclic hardening response, as shown in Figure 5c. However, when the total strain amplitude continues to increase to 0.08 , a short stable period appears at the end of the cyclic stress response curves. Because the cyclic stress amplitude would rapidly rise to a high value, lots of primary $\gamma^{\prime}$ phases would be sheared and the order of primary $\gamma^{\prime}$ phases is reduced, which could decrease the strengthening effects of the superalloy and cause a softening effect on the superalloy [33].

\subsection{The Effect of Grain Refinement on the LCF Property and Fracture of IN792 Superalloy}

According to microstructure observation, the grain refinement of IN792 superalloys through reducing the melting temperature and pouring temperature not only caused increased grain boundary contents, but also the refining of MC carbides, eutectic structures and dendritic structures. The $\gamma^{\prime}$ phases are not refined because they are reprecipitated during the heat treatment process, and the same heat treatment process is employed for CG and FG alloys. As for fracture surface observation, the LCF fracture mode of IN792 superalloys in the present research is all transgranular. The microstructure of the longitudinal section of LCF fractured specimens show that there is no crack formed at grain boundary. The fine granular $\mathrm{M}_{5} \mathrm{~B}_{3}$ borides dispersed at grain boundary are very stable during the whole LCF process, which would play a pinning and strengthening role in the grain boundary and prevent it from cracking. Therefore, it can be deduced that the grain boundary strength is higher than the grain interior under the present test conditions. The refining of grains could increase the grain boundary contents, and improve the overall strength and crack growth resistance of IN792 superalloys.

As determined in our previous study [10], the porosities near the sample surface are major HCF crack initiation sites of IN792 superalloys because they could cause stress concentration in the surrounding areas. The LCF fracture mode under low total strain amplitude is similar to HCF regime. Thus, the size and distribution of porosities is very important to the LCF properties. The casting defects observation of CG and FG alloys proved that even though the reducing the melting and pouring temperature could reduce the mobility of the alloy melt and improve the porosity formation tendency, the porosities near the specimen surface does not show much difference, as indicated in Figure 4 . The porosities near the center of the specimen would not cause fatigue fracture in the present 
study; therefore, the increase in porosity content for FG alloy does not show significant influence on the LCF properties of IN792 superalloys.

It has been reported [37-40] that MC carbides distributed at the interdendritic region and grain boundary could strengthen the superalloy. However, as a microstructure heterogeneity which is incoherent with matrix, it would also cause cyclic plastic strain localization and crack during fatigue tests. The refining of MC carbides could decrease the surrounding cyclic plastic strain localization and thus decrease the crack formation tendency. In addition, the fracture surface observation has shown that the fatigue crack would propagate along interdendritic region under a high total strain amplitude. Since the grain refinement has refined the interdendritic region, the crack propagation would encounter larger hindrance, which would contribute to a longer fatigue life. The refined eutectic structure of FG alloys could also decrease the crack growth tendency because eutectic structure has a relatively low strength. In conclusion, the refinement of MC carbides, eutectic structures and dendritic structures caused by grain refinement could also contribute to the improvement of LCF properties of IN792 superalloy.

\section{Conclusions}

In this study, IN792 superalloys with two different grain sizes were manufactured through different melting and pouring temperatures, and their microstructures are charactered and LCF properties are tested under $700{ }^{\circ} \mathrm{C}$ and $800{ }^{\circ} \mathrm{C}$. The following results are obtained:

(1) Through decreasing melting and pouring temperatures, the grains, MC carbides, eutectic structures and dendritic structures are refined simultaneously, but the primary and secondary $\gamma^{\prime}$ phases stay consistent due to the same heat treatment process.

(2) The LCF properties of $700{ }^{\circ} \mathrm{C}$ and $800{ }^{\circ} \mathrm{C}$ are optimized under four different total strain amplitudes by grain refinement.

(3) The LCF fracture mode is related to the applied total strain amplitude. Under low total strain amplitude, the fatigue cracks mainly initiate at the porosities near the specimen surface, while under high total strain amplitude, the fatigue cracks tend to form at the center of the specimen, and propagate along interdendritic regions.

(4) When the total strain amplitude is low, the dislocations could move in the $\gamma$ channel and form dislocation networks. When the total strain amplitude is high, the dislocations could shear primary $\gamma^{\prime}$ phases and form stacking faults.

(5) The results obtained in the present study could provide theoretical guidance for improving the service performance of IN792 superalloys.

Author Contributions: Conceptualization, L.S. and C.C.; methodology, B.D. and Z.H.; validation, B.D. and Z.H.; formal analysis, B.D. and L.S.; investigation, B.D. and Z.H.; resources, C.C. and X.S.; data curation, B.D.; writing-original draft preparation, B.D.; writing-review and editing, B.D. and L.S.; supervision, L.S. All authors have read and agreed to the published version of the manuscript.

Funding: This research was funded by the National Key Research and Development Program of China (2018YFC1106702, Natural Science Foundation of Guangdong Province, China (2020A1515011301, 2019A1515110067, 2018A0303100018 and 2018A030313950), Shenzhen Basic Research Project (JCYJ20200109144608205, JCYJ20170815153143221 and JCYJ20210322085719002), IER Foundation (HT-JD-CXY-201902 and HT-JD-CXY-201907).

Institutional Review Board Statement: Not applicable.

Informed Consent Statement: Not applicable.

Data Availability Statement: Data are available upon request from the corresponding author.

Conflicts of Interest: The authors declare no conflict of interest. 


\section{References}

1. Wang, J.; Zhou, L.; Sheng, L.; Guo, J. The microstructure evolution and its effect on the mechanical properties of a hot-corrosion resistant Ni-based superalloy during long-term thermal exposure. Mater. Design 2012, 39, 55-62. [CrossRef]

2. Phillips, P.; Unocic, R.; Mills, M. Low cycle fatigue of a polycrystalline Ni-based superalloy: Deformation substructure analysis. Int. J. Fatigue 2013, 57, 50-57. [CrossRef]

3. Sheng, L.; Yang, F.; Guo, J.; Xi, T.F. Anomalous yield and intermediate temperature brittleness behaviors of directionally solidified nickel-based superalloy. Trans. Nonferrous Met. Soc. China 2014, 24, 673-681. [CrossRef]

4. Unocic, R.; Viswanathan, G.; Sarosi, P.; Karthikeyan, S.; Li, J.; Mills, M. Mechanisms of creep deformation in polycrystalline Ni-base disk superalloys. Mater. Sci. Eng. A 2008, 483-484, 25-32. [CrossRef]

5. Ma, Y.; Sun, J.; Xie, X.; Hu, Y.; Zhao, J.; Yan, P. An investigation on fine-grain formation and structural character in cast IN718 superalloy. J. Mater. Process. Technol. 2003, 137, 35-39. [CrossRef]

6. Jiang, R.; Everitt, S.; Lewandowski, M.; Gao, N.; Reed, P. Grain size effects in a Ni-based turbine disc alloy in the time and cycle dependent crack growth regimes. Int. J. Fatigue 2014, 62, 217-227. [CrossRef]

7. Sheng, L.Y.; Zhang, W.; Guo, J.T.; Wang, Z.S.; Ovcharenko, V.E.; Zhou, L.Z.; Ye, H.Q. Microstructure and mechanical properties of $\mathrm{Ni}_{3} \mathrm{Al}$ fabricated by thermal explosion and hot extrusion. Intermetallics 2009, 17, 572-577. [CrossRef]

8. Wei, C.; Bor, H.; Ma, C.; Lee, T. A study of IN-713LC superalloy grain refinement effects on microstructure and tensile properties. Mater. Chem. Phys. 2003, 80, 89-93. [CrossRef]

9. Torster, F.; Baumeister, G.; Albrecht, J.; Lütjering, G.; Helm, D.; Daeubler, M. Influence of grain size and heat treatment on the microstructure and mechanical properties of the nickel-base superalloy U 720 LI. Mater. Sci. Eng. A 1997, 234-236, 189-192. [CrossRef]

10. Du, B.; Yang, J.; Cui, C.; Sun, X. Effects of grain size on the high-cycle fatigue behavior of IN792 superalloy. Mater. Des. 2015, 65, 57-64. [CrossRef]

11. Du, B.; Yang, J.; Cui, C.; Sun, X. Effects of grain refinement on the microstructure and tensile behavior of K417G superalloy. Mater. Sci. Eng. A 2015, 623, 59-67. [CrossRef]

12. Morrison, D.; Moosbrugger, J. Effects of grain size on cyclic plasticity and fatigue crack initiation in nickel. Int. J. Fatigue 1997, 19, 51-59. [CrossRef]

13. Quested, P.N.; Osgerby, S. Mechanical properties of conventionally cast, directionally solidified, and single-crystal superalloys. Mater. Sci. Tech. 1986, 2, 461-475. [CrossRef]

14. Jiao, J.; Zou, Q.; Ye, Y.; Xu, Z.; Sheng, L. Carbon fiber reinforced thermoplastic composites and TC4 alloy laser assisted joining with the metal surface laser plastic-covered method. Compos. Part B Eng. 2021, 213, 108738. [CrossRef]

15. Larson, J.M.; Floreen, S. Metallurgical factors affecting the crack growth resistance of a superalloy. Met. Mater. Trans. A 1977, 8 , 51-55. [CrossRef]

16. Soula, A.; Renollet, Y.; Boivin, D.; Pouchou, J.-L.; Locq, D.; Caron, P.; Bréchet, Y. Analysis of high-temperature creep deformation in a polycrystalline nickel-base superalloy. Mater. Sci. Eng. A 2009, 510-511, 301-306. [CrossRef]

17. Zhao, H.; Sheng, L. Microstructure and mechanical properties of the Ag/316L composite plate fabricated by explosive welding. $J$. Manuf. Process. 2021, 64, 265-275. [CrossRef]

18. Thibault, K.; Locq, D.; Caron, P.; Boivin, D.; Renollet, Y.; Bréchet, Y. Influence of microstructure on local intra- and intergranular deformations during creep of a nickel-based superalloy at $700{ }^{\circ} \mathrm{C}$. Mater. Sci. Eng. A 2013, 588, 14-21. [CrossRef]

19. Shingledecker, J.; Evans, N.; Pharr, G. Influences of composition and grain size on creep-rupture behavior of Inconel ${ }^{\circledR}$ alloy 740 . Mater. Sci. Eng. A 2013, 578, 277-286. [CrossRef]

20. Du, B.N.; Yang, J.X.; Cui, C.Y.; Sun, X.F. Effects of Grain Refinement on Creep Properties of K417G Superalloy. Acta Metall. Sin. 2014, 50, 1384-1392.

21. Kobayashi, K.; Yamaguchi, K.; Hayakawa, M.; Kimura, M. Grain size effect on high-temperature fatigue properties of alloy718. Mater. Lett. 2005, 59, 383-386. [CrossRef]

22. Chan, K.S. Roles of microstructure in fatigue crack initiation. Int. J. Fatigue 2010, 32, 1428-1447. [CrossRef]

23. Du, B.; Shi, Z.; Yang, J.; Chu, Z.; Cui, C.; Sun, X.; Sheng, L.; Zheng, Y. M5B3 Boride at the Grain Boundary of a Nickel-based Superalloy. J. Mater. Sci. Technol. 2016, 32, 265-270. [CrossRef]

24. Du, B.; Sheng, L.; Cui, C.; Yang, J.; Sun, X. Precipitation and evolution of grain boundary boride in a nickel-based superalloy during thermal exposure. Mater. Charact. 2017, 128, 109-114. [CrossRef]

25. Du, B.; Hu, Z.; Sheng, L.; Cui, C.; Yang, J.; Zheng, Y.; Sun, X. Tensile, creep behavior and microstructure evolution of an as-cast Ni-based K417G polycrystalline superalloy. J. Mater. Sci. Technol. 2018, 34, 1805-1816. [CrossRef]

26. Kunz, L.; Lukáš, P.; Konečná, R.; Fintová, S. Casting defects and high temperature fatigue life of IN713LC superalloy. Int. J. Fatigue 2012, 41, 47-51. [CrossRef]

27. Collini, L.; Pirondi, A.; Bianchi, R.; Cova, M.; Milella, P. Influence of casting defects on fatigue crack initiation and fatigue limit of ductile cast iron. Procedia Eng. 2011, 10, 2898-2903. [CrossRef]

28. He, L.; Zheng, Q.; Sun, X.; Guan, H.; Hu, Z.; Tieu, A.; Lu, C.; Zhu, H. High temperature low cycle fatigue behavior of Ni-base superalloy M963. Mater. Sci. Eng. A 2005, 402, 33-41. [CrossRef]

29. Du, B.; Sheng, L.; Hu, Z.; Cui, C.; Yang, J.; Sun, X. Investigation on the microstructure and tensile behavior of a Ni-based IN792 superalloy. Adv. Mech. Eng. 2018, 10, 1-8. [CrossRef] 
30. Caron, P.; Khan, T.; Veyssière, P. On precipitate shearing by superlattice stacking faults in superalloys. Philos. Mag. A 1988, 57, 859-875. [CrossRef]

31. Wang, K.; Jing, H.; Xu, L.; Han, Y.; Zhao, L.; Song, K. Cyclic response and dislocation evolution of a nickel-based superalloy under low cycle fatigue deformation. Mater. Sci. Eng. A 2021, 814, 141225. [CrossRef]

32. Chen, L.J.; Wang, Z.G.; Yao, G.; Tian, J.F. Investigation on high temperature low cycle fatigue properties of a casting nickel base superalloy K417. Acta Metall. Sin. 1999, 35, 1144-1150.

33. Yao, J.; Guo, J.T.; Yuan, C.; Li, Z.J. Low cycle fatigue behavior of cast nickel base superalloy K52. Acta Metall. Sin. 2005, 41, 357-362.

34. Liu, L.; Meng, J.; Liu, J.; Zhang, H.; Sun, X.; Zhou, Y. Investigation on low cycle fatigue behaviors of the [001] and [011] oriental single crystal superalloy at $760{ }^{\circ}$ C. Mater. Sci. Eng. A 2018, 734, 1-6. [CrossRef]

35. Du, B.; Hu, Z.; Sheng, L.; Xu, D.; Qiao, Y.; Wang, B.; Wang, J.; Zheng, Y.; Xi, T. Microstructural characteristics and mechanical properties of the hot extruded Mg-Zn-Y-Nd alloys. J. Mater. Sci. Technol. 2021, 60, 44-55. [CrossRef]

36. Du, B.; Hu, Z.; Wang, J.; Sheng, L.; Zhao, H.; Zheng, Y.; Xi, T. Effect of extrusion process on the mechanical and in vitro degradation performance of a biomedical Mg-Zn-Y-Nd alloy. Bioact. Mater. 2020, 5, 219-227. [CrossRef]

37. Qin, X.; Guo, J.; Yuan, C.; Chen, C.; Hou, J.; Ye, H. Decomposition of primary MC carbide and its effects on the fracture behaviors of a cast Ni-base superalloy. Mater. Sci. Eng. A 2008, 485, 74-79. [CrossRef]

38. Liu, L.; Jin, T.; Zhao, N.; Sun, X.; Guan, H.; Hu, Z. Formation of carbides and their effects on stress rupture of a Ni-base single crystal superalloy. Mater. Sci. Eng. A 2003, 361, 191-197. [CrossRef]

39. He, L.; Zheng, Q.; Sun, X.; Guan, H.; Hu, Z.; Tieu, A.; Lu, C.; Zhu, H. Effect of carbides on the creep properties of a Ni-base superalloy M963. Mater. Sci. Eng. A 2005, 397, 297-304. [CrossRef]

40. Wang, J.; Zhou, L.; Qin, X.; Sheng, L.; Hou, J.; Guo, J. Primary MC decomposition and its effects on the rupture behaviors in hot-corrosion resistant Ni-based superalloy K444. Mater. Sci. Eng. A 2012, 553, 14-21. [CrossRef] 